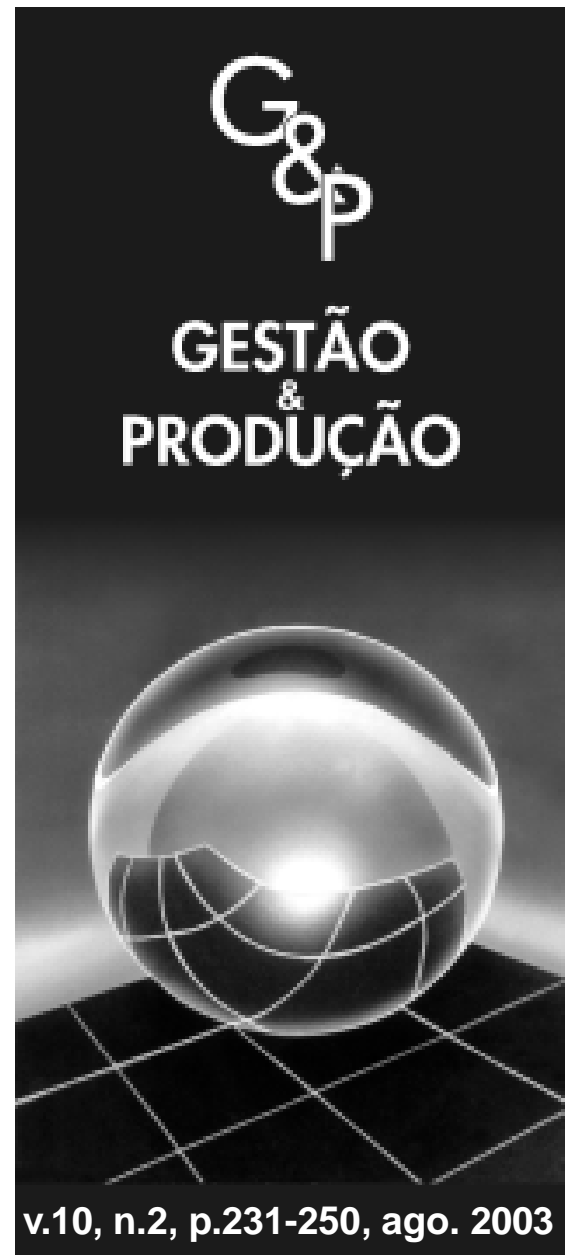

\title{
AVALIANDO A EFICIÊNCIA DAS LOJAS DA ECT DO RIO GRANDE DO SUL
}

\author{
Denis Borenstein \\ João Luiz Becker \\ Escola de Administração, UFRGS, Rua Washington Luis, \\ 855, CEP 90010-460, Porto Alegre, RS, \\ e-mails: denisb@ea.ufrgs.br e jlbecker@ea.ufrgs.br \\ Vaner José do Prado \\ Empresa Brasileira de Correios e Telégrafos
}

Recebido em 12/7/2002

Aceito em 11/6/2003

\section{Resumo}

As empresas postais do mundo inteiro têm procurado métodos capazes de dar sustentação a suas práticas para garantia e ampliação de seus mercados. A Empresa Brasileira de Correios e Telégrafos (ECT), criada em 1969, configurada com muitas lojas similares em todo o Brasil, as quais prestam e comercializam um conjunto de produtos e serviços semelhantes, mas que utilizam recursos diversos em intensidade diferente, possui sua atual avaliação de desempenho das lojas centrada em um único fator economico financeiro, denominado de Índice de Receitas e Despesas $(R / D)$. Esse índice não considera fatores que estão sendo utilizados pelas lojas, fora da visão financeira. Dessa forma, neste artigo, propõe-se avaliar um conjunto de lojas da ECT do Rio Grande do Sul por meio de modelagem matemática, utilizando a técnica Data Envelopment Analysis (DEA - Análise Envoltória de Dados), que possibilita a inclusão de outras variáveis fora da visão econômica. Este trabalho tem por objetivo: 1. definir que variáveis podem ser utilizadas para a avaliação das lojas; 2. definir um conjunto de lojas similares, que executam as mesmas funções e que se diferenciam somente na intensidade da utilização dos recursos; 3. gerar, por meio da técnica, os resultados da avaliação, obtidos a partir dos fatores quantitativos definidos, realizando análises de sensibilidades; e 4. propiciar aos administradores um referencial para apoio à decisão. A utilização da técnica tornou possível: identificar fatores usados de forma distinta nas lojas; identificar práticas utilizadas pelas lojas $100 \%$ eficientes, que podem contribuir para as lojas não eficientes; e permitir e encorajar a participação dos gestores locais na alteração e extensão do modelo, levando em conta as características das lojas.

Palavras-chave: análise de eficiência, análise envoltória de dados, administração de serviços. 


\section{Introdução}

A indústria de correios no mundo é uma complexa atividade que conta com a maior força de trabalho dentre todos os setores da economia mundial, representada por 6,1 milhões de empregados (ECT, 1999). A perspectiva de crescimento anual para o setor é de $2,5 \%$ e $3,8 \%$, respectivamente, para o mercado de cartas domésticas e internacionais; e 5\% para o segmento de encomendas, até o ano de 2005. A universalização dos serviços é considerada um dos maiores desafios das empresas do setor, com a meta de distribuir diariamente cartas e encomendas de até $10 \mathrm{~kg}$ para pessoas físicas e jurídicas, a preços acessíveis, e de entregar, por prestadores de serviços universais, em cada domicílio, jornais, revistas e encomendas de até $20 \mathrm{~kg}$ (Cosquer, 1997).

O atraso relativo de nosso país deverá ser necessariamente superado por meio da eficiência de seus organismos, como condição para retomar o processo de desenvolvimento (Brasil, 1994, 1998). Com este intuito, o programa de recuperação e ampliação do sistema de telecomunicações e do sistema postal - PASTE - prevê investimentos na modernização de serviços telefônicos e dos correios, implantando sistemas abrangentes e rápidos nas diversas modalidades de comunicação, plenamente integrados às redes mundiais (Brasil, 1995). É evidente a importância estratégica da Empresa Brasileira de Correios e Telégrafos (ECT) para o desenvolvimento econômico, social e cultural do País, como atestam as inúmeras parcerias da ECT com o Governo Federal: entrega de livros didáticos para a Fundação Nacional de Educação (FNDE); coleta e entrega, em todo o País, de urnas eletrônicas para votações nas eleições de 1998 e 2000; entrega de mudas de pau-brasil para todas as escolas do país, atividade inserida no projeto Brasil 500 anos; dentre outras. Para o setor privado, a ECT tem lançado novos produtos e serviços voltados a atender suas demandas, como os serviços exporte fácil, que visam a facilitar as exportações tanto de mercadorias como de amostras, e o e-sedex, voltado para atender ao segmento de comércio eletrônico, além do aperfeiçoamento dos serviços tradicionais, como mala-direta, serviços de entrega de impressos e documentos, dentre outros.

As lojas da ECT constituem a célula básica de todo o sistema postal brasileiro, pois é por intermédio delas que são atendidos os diversos segmentos da sociedade em suas variadas necessidades e demandas. Para que suas lojas estejam preparadas e sejam capazes de prestar serviços de qualidade, que atendam aos padrões exigidos por seus clientes, a ECT tem investido massivamente em novas tecnologias, treinamento, melhorias físicas das lojas, veículos e lançamento de novos produtos e serviços, procurando constantemente melhorar seus processos internos e externos por meio da otimização de seus recursos. Contudo, na percepção da diretoria, dos gerentes das lojas e dos administradores do Rio Grande do Sul, o indicador tradicionalmente usado para mensurar o desempenho das lojas, denominado índice R/ D de receita sobre despesa (ECT, 1990), tem se mostrado demasiadamente limitado, pois somente leva em conta seu desempenho financeiro. Há necessidade de considerar outros fatores relevantes, desenvolvendo novas abordagens. Diante da significativa importância que as lojas da ECT exercem dentro do sistema, é necessário que essas novas abordagens respondam às seguintes questões: 1. Como avaliar a performance individual das lojas? 2. Como comparar a performance de uma loja à de outra? 3. Como identificar lojas ou grupos de lojas que possuam excelente grau de desempenho, podendo servir de referencial ou benchmarking para as demais?

O objetivo deste trabalho é demonstrar a aplicação da técnica Análise Envoltória de Dados (DEA - Data Envelopment Analysis) para avaliar a eficiência relativa das lojas da ECT do Rio Grande do Sul. A idéia é aplicar um método de avaliação de eficiência relativa das lojas que possa analisar fatores que estejam fora da visão meramente financeira, levando em consideração outros fatores, gerenciais e ambientais, que possam interferir no desempenho das lojas. A utilização da técnica DEA tem permitido aos adminis- 
tradores a criação de cenários para situações existentes, que possam auxiliar na busca da melhor eficiência possível, facilitando a comparação entre as unidades analisadas e proporcionando visão ampla dos pontos fortes e fracos dentro de cada unidade de análise (Cooper et al., 1999). Essa aplicação nas lojas da ECT do Rio Grande do Sul tem por objetivo selecionar variáveis que contribuam estrategicamente para avaliar o desempenho de um conjunto de lojas, buscando identificar um subconjunto destas que possa servir de referencial. Complementarmente, por meio do estudo das práticas gerenciais e organizacionais das lojas analisadas (eficientes e ineficientes), espera-se melhorar o desempenho de todo o conjunto de lojas. O trabalho limita-se ao Rio Grande do Sul por conveniência, especialmente no que diz respeito à disponibilidade de dados e de tempo para efetuar visitas às lojas e entrevistar seus gerentes. Posteriormente, o modelo desenvolvido poderá ser estendido para outras regiões.

Este artigo contribui com a literatura sobre DEA ao estabelecer conexões entre os resultados quantitativos obtidos por técnica e práticas gerenciais adotadas por gerentes para a gestão estratégica, tática e operacional de suas lojas. A comparação de várias práticas gerenciais e organizacionais empregadas por gestores em lojas eficientes e ineficientes permitiu identificar quais delas contribuem para a obtenção de eficiência.

O trabalho se organiza da seguinte forma: na seção 2 apresenta-se a contextualização do estudo, focalizando a ECT; na seção 3 são rapidamente apresentadas: a técnica DEA e suas aplicações; na seção 4 discute-se a metodologia do estudo; o modelo de avaliação é desenvolvido na seção 5, com definição das unidades de análise, seleção dos fatores de avaliação e descrição das variáveis de input e output escolhidas, a coleta dos dados e a aplicação da técnica DEA; na seção 6 são analisados os resultados, incluindo análise de benchmarking, além de comparação entre as avaliações, usando o índice R/D e a técnica DEA; na seção 7 são avaliados os resultados; a seção 8 oferece algumas sugestões para o aperfeiçoamento do modelo de avaliação aplicado na ECT; finalmente, a seção 9 encerra o trabalho, apresentando algumas conclusões, contribuições e recomendações para estudos futuros e extensões do modelo.

\section{Contextualização do estudo}

A ECT tem sede em Brasília, onde se localiza seu centro de administração nacional, denominado de administração central (AC), congregando todo o sistema nacional de correios. Seu papel fundamental é realizar as definições corporativas da empresa. A ECT conta ainda com 24 diretorias regionais (DR), com sede nas capitais dos principais Estados brasileiros, com a finalidade de coordenar as ações e diretrizes da AC. Embora as DR apresentem estruturas diferenciadas nacionalmente, pelo tamanho ou grau de complexidade das operações em cada Estado, elas executam atividades ou funções semelhantes. As DR estão divididas em regiões operacionais (REOP), com base em fatores geográficos, número de lojas coordenadas, grau de complexidade das operações ou definição estratégica. Às REOP cabe a tarefa de coordenar as atividades das lojas, que, por sua vez, cumprem o papel mais importante dentro da estrutura da ECT, pois a elas cabe a prestação de serviços aos clientes, seja na atividade de atendimento ou de distribuição de objetos. A rede de lojas está configurada sob duas formas, lojas próprias e lojas de terceiros, aquelas sendo geridas exclusivamente pela ECT, enquanto estas se constituem em parcerias com outras organizações e trabalham sob a supervisão técnica da ECT. Há duas formas de lojas de terceiros: a franqueada e a contratada para prestação de serviços. $\mathrm{O}$ contrato pode ser feito com entidades públicas ou privadas, dependendo do interesse da ECT e da necessidade de atender à sociedade. 
Tendo em vista a quantidade de lojas, o volume de recursos que lhes são disponibilizados ou nelas investidos e a importância que representam para o sistema, é procedente a preocupação com a avaliação de sua eficiência. Em princípio, a avaliação deve possibilitar a criação de um conjunto de práticas capazes de gerar aprendizado, propiciar troca de conhecimento entre as lojas e servir como referencial para os administradores. Atualmente, o indicador de eficiência utilizado pela ECT para medir o desempenho das lojas, REOP e DR, é o índice R/D (ECT, 1990). Trata-se, simplesmente, do resultado da divisão das receitas auferidas pelas despesas realizadas, tendo como fronteira o referencial 1. Para uma loja ser considerada eficiente, basta apresentar índice R/D acima de 1. No Rio Grande do Sul, observando dados históricos mensais de 1999, constata-se que um terço das lojas, em média, é deficitário, apresentando índice R/ $\mathrm{D}$ menor que 1. Obviamente, isso não significa que as outras lojas sejam eficientes sob o ponto de vista gerencial. O R/D é um índice agregado, apurado exclusivamente em termos financeiros, que despreza ou não consegue distinguir outros fatores que possam influenciar no desempenho de uma loja. Fatores como qualidade de serviços, satisfação dos clientes, grau de utilização dos recursos disponíveis, carga de trabalho, área utilizada para produzir e outros não são capturados.

$\mathrm{O}$ índice R/D, com as inúmeras transformações do setor postal, tem se mostrado insuficiente para responder às questões estratégicas da ECT. Assim, diante de todos os investimentos que a empresa vem realizando, é fundamental a consideração das seguintes questões: 1 . Como mensurar a utilização dos recursos em cada loja? 2. Como distinguir lojas eficientes de lojas ineficientes? 3. Como comparar lojas eficientes e ineficientes? 4. Onde e quais recursos podem estar sendo alocados inadequadamente? 5. Qual conjunto de lojas pode servir de parâmetro para a administração regional? 6. Que referenciais terá a administração regional para buscar equilíbrio na performance das lojas?

\section{Data envelopment analysis (DEA)}

O DEA é uma técnica de programação matemática desenvolvida por Charnes, Cooper \& Rhodes (1978) e utilizada para medir a eficiência relativa de unidades organizacionais, com a presença de vários inputs e outputs. Charnes et al. (1994) definem DEA como uma técnica para a mensuração da eficiência relativa de unidades similares (que executam as mesmas funções, subordinadas a um órgão controlador) denominadas unidades de tomada de decisão (DMU - decision making units). Essas DMU podem ser empresas, agências bancárias, hospitais, pessoas, etc. O uso dessa ferramenta, dependendo dos objetivos do estudo, possibilita: 1. determinar quantitativamente a eficiência relativa de cada DMU, sob a forma de taxa; 2. identificar origens e quantidades de ineficiência relativa em cada DMU, em qualquer das dimensões de input e output; e 3. apoiar o planejamento de metas para as diversas dimensões que maximizem a eficiência de cada DMU.

As DMU escolhidas precisam estar alinhadas e desempenhando funções semelhantes, devendo, a partir da utilização de uma série de inputs, ser capazes de produzir um conjunto de outputs. Um fator importante a ser considerado é a escolha das variáveis que serão utilizadas como input e output, já que poderão ser levados em conta fatores controláveis (de gestão) e fatores não controláveis (do ambiente), tanto quali como quantitativos.

Recente revisão da literatura aponta algumas vantagens na utilização da técnica DEA, como: 1. os dados não necessitam de normalização, o que é necessário em abordagens econométricas; 2 . a técnica DEA é uma abordagem não paramétrica, não exigindo uma forma funcional explícita relacionando input e output; 3. a técnica DEA pode, explicitamente, apontar a eficiência do processo de produção relacionada aos investimentos; 4 . a técnica DEA é flexível, permitindo a inclusão ou 
exclusão de variáveis; 5. é possível redefinir grupos de unidades avaliadas; 6 . há possibilidade de alteração nos inputs e outputs relativamente a pesos; e 7. o resultado final não apenas pode sinalizar a não eficiência, mas também apontar possíveis melhoramentos que poderão ser implementados (Maçada \& Becker, 1999; Bandeira et al., 2001).

A técnica DEA consiste na resolução de um conjunto de problemas de programação linear fracional (Charnes et al., 1978).

Para $K=1,2, \ldots, N$ :

$\operatorname{Max} \mathrm{h}_{\mathrm{K}}=\frac{\sum_{\mathrm{j}=1}^{\mathrm{n}} \mathrm{w}_{\mathrm{j}} \mathrm{y}_{\mathrm{jK}}}{\sum_{\mathrm{i}=1}^{\mathrm{m}} \mathrm{v}_{\mathrm{i}} \mathrm{x}_{\mathrm{iK}}}$

sujeito a $\frac{\sum_{\mathrm{j}=1}^{\mathrm{n}} \mathrm{w}_{\mathrm{j}} \mathrm{y}_{\mathrm{jk}}}{\sum_{\mathrm{i}=1}^{\mathrm{m}} \mathrm{v}_{\mathrm{i}} \mathrm{x}_{\mathrm{ik}}} \leq 0 \quad k=1,2, \ldots, N$ $\mathrm{v}_{\mathrm{i}}, \mathrm{w}_{\mathrm{j}} \geq \varepsilon \quad i=1,2, \ldots, m ; j=1,2, \ldots, n$

Os problemas anteriores são equivalentes a um conjunto de problemas tradicionais de programação linear:

$\operatorname{Max} \sum_{j=1}^{n} w_{j} y_{j K}$

sujeito a $\sum_{\mathrm{j}=1}^{\mathrm{n}} \mathrm{w}_{\mathrm{j}} \mathrm{y}_{\mathrm{jk}}-\sum_{\mathrm{i}=1}^{\mathrm{m}} \mathrm{v}_{\mathrm{i}} \mathrm{x}_{\mathrm{ik}} \leq 0 k=1,2, \ldots, N$

$\mathrm{K}=1,2, \ldots, N ; i=1,2, \ldots, m ; j=1,2, \ldots, n$

$\mathrm{v}_{\mathrm{i}}, \mathrm{w}_{\mathrm{j}} \geq \varepsilon$

em que:

$N$ é o número de DMU;

$m$ é o número de variáveis de input;

$x_{i k}$ é a quantidade de input $i$ usada pela DMU $k$;

$n$ é o número de variáveis de output; $y_{j k}$ é a quantidade de output $j$ gerada pela DMU $k$;

$v_{i}$ é o peso associado ao input $i$;

$w_{j}$ é o peso associado ao output $j$;

$\varepsilon$ é um número positivo e pequeno.

Diante dos resultados alcançados em inúmeras aplicações da técnica DEA (Seiford, 1997), acredita-se ser possível, por meio dessa ferramenta, avaliar a eficiência relativa das lojas da ECT do Rio Grande do Sul, conforme propósito deste trabalho, permitindo apoiar o planejamento de metas para as diversas dimensões, que maximizem a eficiência de cada DMU.

\section{Metodologia}

Este trabalho usou como base a metodologia de resolução de problemas desenvolvida no âmbito da pesquisa operacional (Ackoff \& Sasieni, 1977), com a proposta de empregar um modelo matemático para avaliar a eficiência relativa das lojas da ECT. Foram utilizadas as etapas clássicas de um estudo de pesquisa operacional: formulação do problema (desejo de avaliar a eficiência relativa das lojas da ECT fora da visão estrita de análise financeira); construção do modelo (ver seção 5); solução do modelo (modelo radial CCR com orientação para input e output, utilizando o software Warwick Windows Dea, 1997); validação do modelo (coleta de dados a partir de documentos oficiais da ECT, criticada quanto à sua confiabilidade nas REOP e variáveis escolhidas em conjunto com algumas REOP, lojas e coordenadores da diretoria regional); e avaliação final (ver seção 7).

\section{Construção do modelo de avaliação}

Esta seção descreve a construção do modelo de programação matemática para a avaliação de eficiência relativa das lojas da ECT do Rio Grande do Sul, com base na técnica DEA. 


\subsection{Definição das unidades de análise}

A partir da observação do conjunto de lojas da ECT no Rio Grande do Sul e de suas características específicas na prestação de serviços, passou-se a aplicar as etapas descritas na seção 4. Em razão das características específicas de cada loja e da disponibilidade de dados, foi preciso dividir as lojas em grupos para melhor estudálas. De um universo de 377 lojas de atendimento no Rio Grande do Sul, foram selecionadas 113 para esta análise. Essas 113 lojas representam cerca de $80 \%$ das receitas da ECT no Estado. Tendo em vista as diferentes características de prestação de serviços das lojas analisadas, elas foram divididas em três grupos, com o objetivo de homogeneizar os fatores de input e output. Os grupos compõem-se de lojas que prestam serviços específicos de atendimento, lojas que prestam serviços específicos de distribuição e lojas integradas que prestam serviços de atendimento e distribuição simultaneamente.

As lojas de atendimento caracterizam-se por prestar somente serviços de atendimento aos clientes, não efetuando distribuição domiciliar. Portanto, não há carteiros em seus quadros de funcionários nem veículos para transporte. São lojas que vendem exclusivamente produtos e outros serviços, constituindo-se lojas de varejo. Esse grupo é composto por 30 lojas (vide Tabela 1).

As lojas de distribuição são caracterizadas por prestar serviços de distribuição domiciliar aos clientes. São lojas que não realizam atendimento de varejo (não comercializam produtos e serviços) e tratam exclusivamente de distribuição domiciliar de objetos, seja por meio de carteiros convencionais (não motorizados) ou de carteiros motorizados (motos e veículos). Foram definidas 28 lojas do interior do Estado, conforme Tabela 2.

As lojas integradas prestam simultaneamente serviços de atendimento e distribuição. São lojas que, em razão de sua estrutura, ainda não contemplam, de acordo com os parâmetros utilizados pela ECT, a separação das atividades conforme os grupos anteriores. Portanto, esse grupo de lojas possui as atividades de prestação de serviços e de vendas de produtos diretamente aos clientes, exercendo, ao mesmo tempo, atividade de distribuição domiciliar de objetos por meio de carteiros convencionais e de carteiros motorizados. Foram analisadas 55 lojas, conforme Tabela 3, distribuídas por todo o Estado do Rio Grande do Sul.

\subsection{Definição e seleção dos fatores de avaliação}

A seleção das variáveis constitui um dos pontos mais críticos para a utilização da técnica DEA, determinando o contexto de avaliação e comparação. Não há, porém, um procedimento-padrão para a execução dessa tarefa. Shafer \& Byrd (2000) sugerem a formação de uma lista inicial de todas as variáveis que possam servir de medida de eficiência. Qualquer fator que possa influenciar ou contribuir para a eficiência das lojas deve constar na lista. Logo após a criação dessa lista, precisase pensar em aproveitar somente aqueles que possam efetivamente contribuir para a avaliação de eficiência da loja, seja por meio do descarte de alguns fatores ou da agregação de outros. Algumas técnicas são úteis para apoiar essa seleção de fatores: focus group (Morgan, 1988), delphi e nominal group technique - NGT (Canada \& Sullivan, 1989), brainstorming (Prazeres, 1996) e outras. Para apoiar a definição das variáveis deste estudo, foi aplicada a técnica de brainstorming com dois coordenadores da diretoria regional da ECT do Rio Grande do Sul, responsáveis pela coordenação e gerenciamento das metas, objetivos e programa de qualidade das regiões operacionais e lojas da ECT.

Nos contatos preliminares com a empresa, verificou-se que seus coordenadores já possuíam um conjunto de fatores considerados relevantes para a ECT, passíveis de serem incluídos durante a criação de uma "cesta de indicadores" de desempenho, que estava em elaboração. Com base nesses fatores foi elaborada uma lista inicial incluindo aqueles que poderiam contribuir para a avaliação, durante duas sessões de brainstorming, 
realizadas nos meses de abril e maio de 2000 com os coordenadores. Esses fatores selecionados encontram-se no Quadro 1.

A partir da definição da lista inicial de fatores considerados relevantes para análise da eficiência relativa das lojas, conforme a classificação de cada grupo de lojas, em conjunto com a administração da empresa, passou-se, então, a buscar dados nas lojas, considerando por base o ano de 1999. Com isso, percebeu-se que alguns dados seriam difíceis, ou até mesmo impossíveis, de serem coletados, por questões de disponibilidade e confiabilidade. Outros perderam sua relevância em função das análises efetuadas, passando a ser igualmente desconsiderados.

Alguns fatores listados inicialmente, como investimento em TI e investimento em infraestrutura (melhoria física das lojas), foram descartados em razão de sua irregularidade, pois não há um programa objetivo que defina antecipadamente quais lojas serão contempladas com esse tipo de investimento. O fator renda per capita foi excluído após a análise com o DEA, por não ser considerado relevante para o modelo, já que o fator não foi capaz de dife- renciar as unidades analisadas. A análise realizada indica que algum ou vários setores da economia dos municípios demonstram crescimento de atividades econômicas, mas isso não faz com que os recursos sejam canalizados para as lojas de correios. Outro fator excluído foi o índice de satisfação com a distribuição domiciliar, por não possuir regularidade de pesquisa em todas as lojas. Esse aspecto representa um processo ainda em estruturação, sendo um importante indicador para as lojas. A taxa de absenteísmo também foi excluída, por não poder ser estratificada por loja, tendo em vista que ainda se encontra genericamente definida por gerência ou região operacional. A carga expedida, por sua vez, está contemplada dentro do sistema de carga de trabalho e também foi excluída, assim como o tempo médio de espera na fila. Esse último fator foi excluído por não ter forma-padrão, regularidade e confiabilidade na coleta dos dados (algumas lojas fazem a medição, outras não). Embora importante, não há uma metodologia de coleta de dados desse fator para que ele possa ser incluído no modelo.

\section{Quadro 1 - Lista inicial de fatores de input e output.}

\begin{tabular}{lll}
\hline \multicolumn{1}{c}{ Input } & & \multicolumn{1}{c}{ Output } \\
\hline - Número de funcionários (nfunc) & - Índice de satisfação dos clientes externos (in_isa) \\
- Número de veículos (n_veíc) & - Programa de qualidade - PMAT (in_pmat) \\
- Investimento em treinamento (h_ep) & - Receita total (receitas) \\
- Investimento em TI (inv_TI) & - População atendida (in_papt) \\
- Área física (áre-fís) & - Carga distribuída (dist) \\
- Custo total (custos) & - Carga expedida (exp) \\
- Investimento em infra-estrutura (infra) & - Número de objetos entregues (objdist) \\
& - Taxa de absenteísmo (abs) \\
& - Tempo médio de espera na fila (tempo_fila) \\
& - Sistema de carga de trabalho (sct) \\
& - Índice de satisfação com a distribuição domiciliar (in_dist) \\
\hline
\end{tabular}


Quadro 2 - Conjunto de variáveis de input e output para cada grupo de lojas.

\begin{tabular}{clccc}
\hline & Variável & Lojas de atendimento & Lojas de distribuição & Lojas integradas \\
\hline \multirow{2}{*}{ input } & nfunc & $\checkmark$ & $\checkmark$ & $\checkmark$ \\
& áre-fís & $\checkmark$ & $\checkmark$ & $\checkmark$ \\
& custos & $\checkmark$ & $\checkmark$ & $\checkmark$ \\
& h_ep & $\checkmark$ & $\checkmark$ & $\checkmark$ \\
& n_veíc & $\checkmark$ & $\checkmark$ \\
\hline \multirow{2}{*}{ output } & in_papt & $\checkmark$ & & $\checkmark$ \\
& in_isa & $\checkmark$ & $\checkmark$ & $\checkmark$ \\
& in_pmat & $\checkmark$ & & $\checkmark$ \\
& receitas & $\checkmark$ & & $\checkmark$ \\
& sct & $\checkmark$ & $\checkmark$ & $\checkmark$ \\
\hline
\end{tabular}

O Quadro 2 apresenta o conjunto final de input e output utilizado para cada grupo de lojas. A definição operacional para cada variável é apresentada no Anexo.

As Tabelas 1, 2 e 3 mostram os valores de cada fator de input e output utilizados na avaliação relativa das lojas de atendimento, de distribuição e integradas, respectivamente. A identidade de cada loja foi preservada, fugindo do escopo deste artigo. Os dados foram obtidos de relatórios oficiais da ECT para os fatores receita total, número de funcionários, custo total, número de veículos, área física, índice de satisfação de clientes externos, horas de treinamento por empregado e pontuação no PMAT. Os dados relativos à população foram obtidos do Instituto Brasileiro de Geografia e Estatística (IBGE), tendo 1996 por ano base (IBGE, 1996). Os dados referentes à população atendida nas lojas e aos objetos distribuídos foram coletados de documentos formais ou compilados diretamente a partir de acompanhamento diário nas lojas. Essa compilação foi realizada pelas regiões operacionais, coordenadoras das lojas. Também foi realizada crítica dos dados recebidos das regiões operacionais e lojas quando algum dado apresentava indício de distorção.

\section{Análise dos resultados}

Os resultados de eficiência relativa obtidos para as lojas de atendimento, de distribuição e integradas apresentam-se nas Tabelas 1, 2 e 3, respectivamente. De maneira geral, as lojas mostram-se eficientes, o que é importante e significativo para a organização. A média dos índices de eficiência das 113 lojas analisadas é igual a 87,1\%, com desviopadrão igual a $16,2 \%$.

Quase metade (44\%) das lojas é 100\% eficiente, $68 \%$ têm índices de eficiência relativa superiores a $80 \%$ e $83 \%$ apresentam índices superiores a $70 \%$. Os índices de eficiência das lojas de atendimento são todos superiores a $70 \%$, sendo que $50 \%$ delas apresentam índices iguais a $100 \%$, com $80 \%$ apresentando índices superiores a 80\%. Já as lojas de distribuição, $50 \%$ delas apresentam índices iguais a $100 \%$, com $64 \%$ apresentando índices superiores a $80 \%$ e $79 \%$, índices superiores a $70 \%$. 
Tabela 1 - Quantitativos finais de input e output das lojas de atendimento.

\begin{tabular}{|c|c|c|c|c|c|c|c|c|c|c|c|c|}
\hline & \multicolumn{4}{|c|}{ Input } & \multicolumn{5}{|c|}{ Output } & \multicolumn{3}{|r|}{ Índices de eficiência } \\
\hline & 总 & 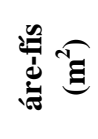 & 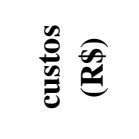 & 릴 & 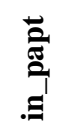 & $\begin{array}{l}\stackrel{g}{2} \\
. \\
\Xi\end{array}$ & $\begin{array}{l}\overrightarrow{\mathrm{E}} \\
. \Xi \\
.\end{array}$ & 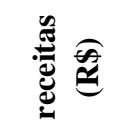 & $\bar{u}_{\mathscr{w}}$ & $\frac{\sqrt{9}}{\sqrt{9}}$ & $\stackrel{\gtrless}{\approx}$ & Lojas utilizadas como pares \\
\hline LA24 & 35 & 800 & 120.079 & 49 & 3,7 & 88 & 978 & 257.739 & 4.960 & 71,9 & 2,14 & LA3; LA11; LA12; LA21 \\
\hline LA10 & 14 & 326 & 37.636 & 20 & 7,7 & 84 & 942 & 83.531 & 1.802 & 72,1 & 2,21 & LA5; LA11; LA19; LA26 \\
\hline LA27 & 15 & 673 & 47.246 & 44 & 4,7 & 91 & 944 & 142.930 & 2.673 & 73,7 & 3,02 & LA3; LA4; LA12; LA30 \\
\hline LA25 & 9 & 339 & 25.235 & 60 & 2,5 & 98 & 89 & 49.541 & 1.255 & 74,7 & 1,96 & LA1; LA14; LA15; LA30 \\
\hline LA6 & 8 & 300 & 29.502 & 59 & 4,0 & 74 & 1.000 & 79.638 & 1.382 & 75,3 & 2,69 & LA5; LA12; LA14; LA30 \\
\hline LA22 & 14 & 490 & 44.204 & 65 & 2,8 & 81 & 465 & 162.560 & 2.620 & 79,8 & 3,67 & LA3; LA4; LA12; LA30 \\
\hline LA16 & 11 & 311 & 30.751 & 61 & 7,9 & 86 & 981 & 58.295 & 1.259 & 81,9 & 1,89 & LA2; LA5 \\
\hline LA23 & 12 & 450 & 38.404 & 39 & 3,3 & 92 & 851 & 148.532 & 2.112 & 84,7 & 3,86 & $\begin{array}{c}\text { LA3; LA5; LA7; LA12; } \\
\text { LA30 }\end{array}$ \\
\hline LA9 & 44 & 1.680 & 114.472 & 57 & 3,4 & 80 & 813 & 455.655 & 6.875 & 88,6 & 3,98 & LA3; LA7; LA12 \\
\hline LA29 & 13 & 512 & 38.728 & 44 & 3,4 & 82 & 980 & 86.654 & 3.143 & 88,9 & 2,23 & LA4; LA11; LA14 \\
\hline LA8 & 9 & 347 & 24.150 & 47 & 5,7 & 99 & 56 & 46.112 & 1.542 & 89,2 & 1,90 & LA2; LA15; LA19 \\
\hline LA13 & 9 & 185 & 24.839 & 75 & 2,3 & 84 & 936 & 106.732 & 1.354 & 92,7 & 4,29 & LA12; LA17; LA30 \\
\hline LA28 & 6 & 200 & 20.261 & 24 & 3,1 & 95 & 958 & 54.548 & 1.265 & 96,8 & 2,69 & LA3; LA5; LA15; LA30 \\
\hline LA20 & 23 & 350 & 74.479 & 62 & 5,3 & 87 & 917 & 238.303 & 4.161 & 99,4 & 3,19 & LA4; LA11; LA12 \\
\hline LA18 & 25 & 806 & 66.712 & 66 & 3,8 & 90 & 932 & 306.790 & 4.989 & 99,5 & 4,59 & LA3; LA4; LA7; LA12 \\
\hline LA1 & 9 & 166 & 18.096 & 61 & 1,8 & 96 & 920 & 71.077 & 1.447 & 100 & 3,92 & \\
\hline LA2 & 7 & 179 & 23.471 & 76 & 7,9 & 88 & 980 & 41.285 & 1.403 & 100 & 1,75 & \\
\hline LA3 & 7 & 251 & 21.124 & 4 & 3,2 & 91 & 682 & 80.193 & 1.535 & 100 & 3,79 & \\
\hline LA4 & 12 & 217 & 33.070 & 52 & 5,1 & 80 & 775 & 136.761 & 3.315 & 100 & 4,13 & \\
\hline LA5 & 7 & 190 & 21.603 & 10 & 6,2 & 90 & 991 & 74.800 & 1.433 & 100 & 3,46 & \\
\hline LA7 & 27 & 1.030 & 60.773 & 41 & 1,6 & 91 & 964 & 301.074 & 4.350 & 100 & 4,95 & \\
\hline LA11 & 9 & 182 & 22.981 & 14 & 4,2 & 95 & 964 & 70.624 & 2.377 & 100 & 3,07 & \\
\hline LA12 & 16 & 262 & 64.203 & 94 & 4,7 & 85 & 882 & 368.981 & 1.822 & 100 & 5,74 & \\
\hline LA14 & 5 & 341 & 17.525 & 43 & 3,6 & 91 & 990 & 59.418 & 1.440 & 100 & 3,39 & \\
\hline LA15 & 7 & 300 & 19.279 & 14 & 4,4 & 97 & 988 & 67.313 & 1.521 & 100 & 3,33 & \\
\hline LA17 & 10 & 146 & 27.005 & 115 & 9,4 & 91 & 1.000 & 77.704 & 1.952 & 100 & 2,87 & \\
\hline LA19 & 9 & 130 & 21.114 & 32 & 6,3 & 90 & 941 & 38.764 & 865 & 100 & 1,83 & \\
\hline LA21 & 24 & 515 & 89.424 & 27 & 1,7 & 78 & 533 & 244.024 & 3.840 & 100 & 2,72 & \\
\hline LA26 & 9 & 95 & 4.486 & 37 & 5,2 & 87 & 888 & 96.456 & 1.399 & 100 & 2,15 & \\
\hline LA30 & 5 & 168 & 18.385 & 28 & 2,0 & 92 & 974 & 78.871 & 1.323 & 100 & 4,28 & \\
\hline Média & 14 & 398 & 39.975 & 47 & 4,4 & 88 & 844 & 136.164 & 2.380 & & & \\
\hline DP & 9 & 330 & 28.563 & 25 & 2,0 & 6 & 247 & 108.402 & 1.454 & & & \\
\hline
\end{tabular}


Tabela 2 - Quantitativos finais de input e output das lojas de distribuição.

\begin{tabular}{|c|c|c|c|c|c|c|c|c|c|c|}
\hline & \multicolumn{5}{|c|}{ Input } & \multicolumn{2}{|c|}{ Output } & \multicolumn{3}{|r|}{ Índices de eficiência } \\
\hline & $\stackrel{巳}{\Xi}$ & 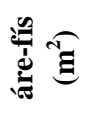 & 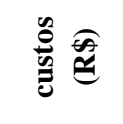 & 의 & $\begin{array}{l}\frac{0}{0} \\
= \\
=\end{array}$ & 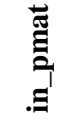 & 莗 & 氛 & $\stackrel{\vartheta}{\beth}$ & Lojas utilizadas como pares \\
\hline LD26 & 80 & 1.200 & 113.627 & 172 & 11 & 762 & 17.144 & 37,3 & N/D & LD3; LD14; LD16; LD22; LD25 \\
\hline LD2 & 41 & 275 & 6.582 & 100 & 8 & 640 & 12.922 & 60,7 & $\mathrm{~N} / \mathrm{D}$ & LD6; LD11; LD22; LD24 \\
\hline LD17 & 61 & 600 & 96.701 & 83 & 8 & 837 & 23.158 & 64,1 & N/D & LD14; LD15; LD22 \\
\hline LD21 & 97 & 800 & 162.076 & 96 & 14 & 851 & 35.902 & 64,4 & $\mathrm{~N} / \mathrm{D}$ & LD6; LD14; LD15 \\
\hline LD10 & 37 & 656 & 53.492 & 116 & 7 & 942 & 12.764 & 67,0 & N/D & LD3; LD7; LD22 \\
\hline LD19 & 65 & 363 & 87.713 & 148 & 14 & 354 & 23.769 & 68,0 & N/D & LD14; LD24 \\
\hline LD28 & 61 & 600 & 73.661 & 48 & 13 & 828 & 18.507 & 72,6 & $\mathrm{~N} / \mathrm{D}$ & LD13; LD15; LD22; LD27 \\
\hline LD20 & 50 & 745 & 83.486 & 46 & 10 & 682 & 20.984 & 73,0 & $\mathrm{~N} / \mathrm{D}$ & LD15; LD27 \\
\hline LD23 & 38 & 750 & 54.202 & 45 & 7 & 822 & 13.432 & 76,9 & $\mathrm{~N} / \mathrm{D}$ & LD13; LD15; LD22; LD27 \\
\hline LD12 & 70 & 500 & 84.942 & 71 & 14 & 954 & 24.751 & 78,3 & $\mathrm{~N} / \mathrm{D}$ & LD6; LD15; LD22; LD27 \\
\hline LD1 & 41 & 320 & 50.779 & 47 & 8 & 920 & 12.463 & 84,3 & $\mathrm{~N} / \mathrm{D}$ & LD6; LD22; LD27 \\
\hline LD5 & 40 & 280 & 52.154 & 86 & 7 & 980 & 16.686 & 89,3 & $\mathrm{~N} / \mathrm{D}$ & LD6; LD9; LD11; LD22 \\
\hline LD8 & 29 & 600 & 48.250 & 30 & 5 & 659 & 13.727 & 89,5 & N/D & LD15; LD22; LD27 \\
\hline LD4 & 29 & 840 & 51.615 & 125 & 6 & 940 & 16.887 & 99,0 & $\mathrm{~N} / \mathrm{D}$ & LD7; LD14; LD22 \\
\hline LD3 & 35 & 479 & 41.070 & 114 & 9 & 770 & 21.596 & 100 & $\mathrm{~N} / \mathrm{D}$ & \\
\hline LD6 & 84 & 320 & 121.109 & 71 & 13 & 986 & 39.010 & 100 & N/D & \\
\hline LD7 & 27 & 465 & 38.692 & 196 & 1 & 980 & 16.758 & 100 & N/D & \\
\hline LD9 & 68 & 400 & 80.747 & 76 & 11 & 937 & 32.200 & 100 & N/D & \\
\hline LD11 & 30 & 222 & 40.397 & 100 & 4 & 964 & 15.965 & 100 & N/D & \\
\hline LD13 & 34 & 816 & 41.786 & 41 & 7 & 865 & 14.494 & 100 & N/D & \\
\hline LD14 & 58 & 525 & 82.501 & 97 & 4 & 791 & 37.087 & 100 & N/D & \\
\hline LD15 & 55 & 532 & 81.300 & 56 & 6 & 912 & 33.515 & 100 & N/D & \\
\hline LD16 & 26 & 346 & 38.409 & 83 & 1 & 982 & 13.004 & 100 & N/D & \\
\hline LD18 & 50 & 288 & 75.069 & 137 & 6 & 987 & 25.200 & 100 & $\mathrm{~N} / \mathrm{D}$ & \\
\hline LD22 & 23 & 236 & 35.623 & 55 & 5 & 964 & 11.697 & 100 & N/D & \\
\hline LD24 & 70 & 386 & 97.745 & 129 & 9 & 932 & 38.512 & 100 & N/D & \\
\hline LD25 & 31 & 240 & 38.157 & 68 & 4 & 950 & 13.700 & 100 & N/D & \\
\hline LD27 & 32 & 360 & 54.212 & 16 & 6 & 960 & 13.749 & 100 & $\mathrm{~N} / \mathrm{D}$ & \\
\hline Média & 49 & 505 & 67.361 & 88 & 7,8 & 862 & 21.056 & & & \\
\hline DP & 20 & 234 & 32.440 & 43 & 3,7 & 144 & 8.930 & & & \\
\hline
\end{tabular}

N/D: Dado não disponível. 
Tabela 3 - Quantitativos finais de input e output das lojas integradas.

\begin{tabular}{|c|c|c|c|c|c|c|c|c|c|c|c|c|c|c|}
\hline & \multicolumn{5}{|c|}{ Input } & \multicolumn{6}{|c|}{ Output } & \multicolumn{3}{|c|}{ Índices de eficiência } \\
\hline & 莺 & 氙 & 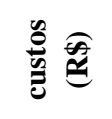 & 离 & 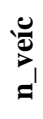 & 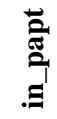 & $\begin{array}{l}\stackrel{\mathscr{m}}{a} \\
. \Xi\end{array}$ & 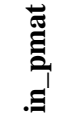 & 氖 & 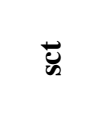 & $\frac{5}{0}$ & 점 & sิ & $\begin{array}{r}\text { as utili } \\
\text { pa }\end{array}$ \\
\hline LI36 & 15 & 0 & 76 & 38 & 2 & & 90 & 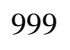 & .001 & & & ,4 & 0,90 & \\
\hline LI40 & 27 & 50 & 515 & 69 & 4 & & 68 & 762 & 50.138 & 1.287 & & 46,9 & 1,12 & 11 \\
\hline LI24 & 14 & 53 & 92 & 53 & 3 & & 86 & 11 & 27.192 & 002 & & 49,3 & 1,00 & LI50 \\
\hline LI43 & 17 & 250 & 31.053 & 101 & 2 & 2,0 & 95 & 834 & 31.611 & 785 & 836 & 49,4 & 1,01 & 19; LI27; LI5 \\
\hline 33 & 19 & 11 & 30.796 & 86 & 4 & & 92 & 50 & 36.702 & 1.498 & & 51,7 & 19 & \\
\hline LI32 & 15 & 230 & 27.701 & 71 & 4 & 4 & 91 & 733 & 37.872 & 89 & 72 & 58,9 & 1,36 & 150 \\
\hline LI45 & 26 & 94 & & 35 & 3 & 7 & 96 & 16 & 895 & & &, 6 & 29 & \\
\hline LI37 & 35 & 850 & 62.244 & 53 & 5 & 1,5 & 90 & 844 & 53.082 & 2.102 & 18 & 61,3 & 0,85 & LI50 \\
\hline LI2 & 17 & 30 & 0 & 52 & 2 & 3,0 & 94 & 4 & 09 & & & 2 & 2 & \\
\hline LI3S & 18 & 4 & 35.664 & 34 & 3 & 1,9 & 89 & 982 & 44.477 & 1.445 & & 62,9 & 1,24 & 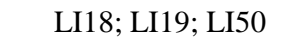 \\
\hline LI1 & 13 & 22 & & 69 & 3 & & 85 & 8 & & & & ,3 & & \\
\hline LI4 & 10 & 82 & 18. & 60 & 2 & 1,9 & 95 & 801 & 24.680 & & & 65,9 & 1,35 & \\
\hline LI4 & 10 & 83 & 144 & 108 & 4 & & 97 & 97 & 922 & & & 69,5 & 1,33 & \\
\hline LI53 & 27 & 336 & 55.751 & 43 & 4 & 1,7 & 85 & 970 & 50.990 & 2.129 & 82 & 70,0 & 0,91 & LI16; \\
\hline LI5 & 16 & 92 & 889 & 67 & 3 & & 92 & 972 & 36.350 & 1.608 & & 74,3 & 1,35 & $\mathrm{I} 50$ \\
\hline LI25 & 13 & 139 & 034 & 56 & 2 & 2,5 & 93 & 691 & 36.727 & 9 & & 74,8 & 1,52 & \\
\hline & 1 & 140 & & 98 & 5 & & 84 & & & & & & 0,90 & \\
\hline LI12 & 12 & 140 & 41 & 38 & 2 & 3,3 & 87 & 890 & 33.729 & 1.198 & 38 & 77,1 & 1,56 & I3; L \\
\hline & 17 & 133 & & 36 & 5 & 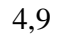 & 92 & & & 1.15 & & & 1,47 & 119 \\
\hline LI9 & 9 & 144 & 205 & 78 & 2 & 5 , & 91 & 942 & 700 & 884 & 1 & 79,9 & 1,80 & I50 \\
\hline & 38 & 900 & & 4 & 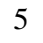 & 0,9 & 80 & 699 & & 2.615 & & 84,0 & & \\
\hline LI46 & 8 & 166 & 57 & 25 & 2 & 3,1 & 100 & 697 & 22.898 & 693 & 19 & 84,5 & 71 & 50 \\
\hline & 12 & 123 & & 2. & 2 & 1 , & 97 & 59 & & & & & 1,46 & 12 \\
\hline LI35 & 13 & 155 & 28.919 & 18 & 2 & 2 & 84 & 918 & 29.480 & 8 & 11 & 86,0 & 1,01 & LI47 \\
\hline LI1 & 26 & 128 & & 109 & 3 & 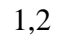 & 80 & . & 51.709 & 1.897 & & 86,2 & 1,00 & LI28; LI3 \\
\hline LI55 & 12 & 310 & 21.685 & 33 & 1 & 4,4 & 81 & 752 & 35.976 & 876 & 2.400 & 88,4 & 1,65 & LI18; LI20; LI27; LI44 \\
\hline LI34 & 13 & 200 & 25.668 & 63 & 3 & 3,0 & 93 & 966 & 60.341 & & & 89,5 & 2,35 & LI18; LI19; LI50 \\
\hline LI1 & 16 & 105 & 209 & 35 & 4 & 3 , & 87 & 902 & 35.107 & 1.020 & 4 & 89,9 & 1,58 & LI22; LI28; LI47; LI50 \\
\hline LI10 & 6 & 150 & 11.063 & 220 & 1 & 4,3 & 100 & 723 & 14.122 & & & 92,3 & 1,27 & LI3; LI27; LI29; LI50 \\
\hline $\mathrm{LI} 7$ & 35 & 738 & 48 & 29 & 6 & . & 91 & 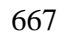 & 24 & 1.963 & & 93,1 & 0,90 & LI16; LI18; LI47; LI50 \\
\hline LI6 & 7 & 125 & 11.788 & 34 & 1 & 4,2 & 89 & 664 & & 0 & & 96,5 & 2,20 & I20; LI27; LI29; LI50 \\
\hline $\mathrm{LI}$ & 10 & 153 & 8 & 88 & 3 & 3, & 83 & 85 & 38 & 9 & 3 & 99,2 & 1,44 & LI3; LI18; LI50 \\
\hline LI31 & 16 & 232 & 26.412 & 101 & 4 & 2,1 & 99 & 999 & 61.529 & 1.418 & 7.615 & 99,3 & 2,32 & LI19; LI22; LI50 \\
\hline
\end{tabular}


Tabela 3 - Quantitativos finais de input e output das lojas integradas (continuação).

\begin{tabular}{|c|c|c|c|c|c|c|c|c|c|c|c|c|c|c|}
\hline & \multicolumn{5}{|c|}{ Input } & \multicolumn{6}{|c|}{ Output } & \multicolumn{3}{|c|}{ Índices de eficiência } \\
\hline & 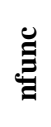 & 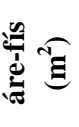 & 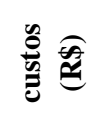 & 월 & $\begin{array}{l}\frac{0}{0} \\
= \\
=\end{array}$ & 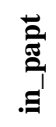 & $\stackrel{g}{.}$ & $\begin{array}{l}\bar{\Xi} \\
\Xi \\
\Xi\end{array}$ & 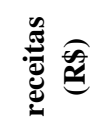 & $\bar{E}_{\mathscr{n}}$ & $\frac{5}{\frac{0}{0}}$ & 종 & 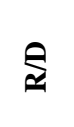 & $\begin{array}{c}\text { Lojas utilizadas como } \\
\text { pares }\end{array}$ \\
\hline LI8 & 13 & 126 & 26.258 & 16 & 2 & 1,7 & 89 & 637 & 28.295 & 1.148 & 4.391 & 99,9 & 1,07 & LI16; LI47; LI50 \\
\hline LI2 & 23 & 120 & 26.479 & 62 & 1 & 2,1 & 97 & 992 & 38.311 & 908 & 7.904 & 100 & 1,45 & \\
\hline LI3 & 5 & 120 & 10.119 & 19 & 1 & 3,3 & 85 & 915 & 11.358 & 446 & 3.347 & 100 & 1,12 & \\
\hline LI4 & 14 & 97 & 19.145 & 27 & 2 & 2,3 & 88 & 560 & 36.937 & 1.044 & 3.200 & 100 & 1,92 & \\
\hline LI13 & 29 & 170 & 46.562 & 62 & 4 & 1,7 & 86 & 766 & 97.312 & 1.793 & 10.508 & 100 & 2,08 & \\
\hline LI14 & 8 & 270 & 13.956 & 119 & 1 & 4,3 & 91 & 854 & 30.042 & 1.206 & 2.200 & 100 & 2,15 & \\
\hline LI16 & 13 & 184 & 21.942 & 22 & 3 & 2,3 & 71 & 607 & 40.281 & 1.789 & 6.000 & 100 & 1,83 & \\
\hline LI17 & 6 & 170 & 10.071 & 44 & 1 & 4,2 & 96 & 831 & 16.393 & 536 & 2.150 & 100 & 1,62 & \\
\hline LI18 & 18 & 154 & 33.561 & 28 & 2 & 3,0 & 89 & 653 & 71.235 & 1.884 & 8.948 & 100 & 2,12 & \\
\hline LI19 & 13 & 140 & 24.262 & 49 & 3 & 4,8 & 99 & 962 & 74.349 & 1.349 & 2.649 & 100 & 3,07 & \\
\hline LI20 & 9 & 140 & 12.632 & 27 & 1 & 4,6 & 91 & 782 & 31.687 & 810 & 2.600 & 100 & 2,50 & \\
\hline LI21 & 7 & 98 & 13.730 & 45 & 2 & 4,4 & 96 & 786 & 17.110 & 585 & 2.525 & 100 & 1,24 & \\
\hline LI22 & 11 & 103 & 14.126 & 20 & 2 & 4,6 & 92 & 932 & 34.731 & 902 & 4.776 & 100 & 2,45 & \\
\hline LI27 & 4 & 160 & 8.742 & 19 & 0 & 3,0 & 98 & 922 & 8.978 & 357 & 573 & 100 & 1,02 & \\
\hline LI28 & 29 & 98 & 46.604 & 117 & 3 & 2,0 & 92 & 972 & 61.595 & 2.113 & 9.332 & 100 & 1,32 & \\
\hline LI29 & 6 & 128 & 8.694 & 43 & 2 & 5,1 & 98 & 719 & 16.929 & 662 & 1.100 & 100 & 1,94 & \\
\hline LI30 & 9 & 216 & 15.987 & 33 & 2 & 2,6 & 67 & 848 & 28.400 & 2.056 & 3.505 & 100 & 1,77 & \\
\hline LI44 & 7 & 200 & 13.634 & 22 & 1 & 5,8 & 83 & 912 & 31.322 & 682 & 1.700 & 100 & 2,29 & \\
\hline LI47 & 24 & 100 & 38.227 & 26 & 2 & 2,2 & 89 & 935 & 54.408 & 1.740 & 11.008 & 100 & 1,42 & \\
\hline LI50 & 7 & 100 & 11.905 & 15 & 1 & 6,6 & 93 & 992 & 27.142 & 1.077 & 3.532 & 100 & 2,28 & \\
\hline LI51 & 10 & 90 & 17.960 & 165 & 1 & 2,8 & 86 & 747 & 22.214 & 718 & 2.557 & 100 & 1,23 & \\
\hline LI52 & 12 & 100 & 20.551 & 41 & 2 & 2,0 & 93 & 824 & 32.106 & 1.342 & 2.553 & 100 & 1,56 & \\
\hline Média & 15 & 216 & 26.539 & 58 & 2,5 & 2,9 & 90 & 831 & 37.631 & 1.167 & 4.665 & & & \\
\hline DP & 8 & 167 & 14.067 & 41 & 1,3 & 1,3 & 7 & 126 & 17.466 & 511 & 2.762 & & & \\
\hline
\end{tabular}

Por outro lado, as lojas integradas revelam-se relativamente menos eficientes, o que, de certa forma, é esperado, dada sua condição híbrida. Apenas 38\% das lojas integradas possuem índices de eficiência relativa iguais a $100 \%$, com $64 \%$ apresentando índices superiores a $80 \%$ e $76 \%$, índices superiores a $70 \%$.

A técnica DEA também aponta possíveis melhorias que poderão ser implementadas em cada fator pelas lojas não $100 \%$ eficientes, visando a melhorar seu desempenho. Bergendahl (1998) afirma que a técnica DEA é uma ferramenta apropriada para benchmarking, pois permite identificar, para cada loja não eficiente, um grupo de lojas eficientes (de certa forma semelhantes àquela) que podem ser utilizadas para definir metas operacionais para a correspondente loja não eficiente, para os diversos fatores de input e de output. Espera-se que os administradores possam analisar práticas organizacionais desse grupo de lojas (denominadas pares) e, adaptando-as para a correspondente loja ineficiente, obter melhorias em sua eficiência futura. É preciso compreender, entretanto, que as metas apontadas pela técnica resultam de abstrações 
embutidas no modelo matemático utilizado, com base nos inputs e outputs selecionados. Cabe aos administradores, com sua perspicácia, usar os resultados como apoio à tomada de decisão, analisando todo o contexto organizacional. A seguir são apontadas as lojas ineficientes e seus referenciais (pares) por conjunto de lojas.

\subsection{Lojas de atendimento}

De acordo com a Tabela 1, depreende-se que algumas lojas $100 \%$ eficientes aparecem como referencial para outras ineficientes com maior frequiência. Por exemplo, a loja LA12 serve de referencial para 9 outras lojas; as lojas LA3 e LA30 aparecem, cada uma, como referencial para outras 7 lojas; a loja LA4 aparece como referencial para outras 5 lojas. Estas são as lojas de atendimento que significativamente aparecem como referencial para outras. Uma análise acurada das práticas gerenciais dessas destacadas lojas certamente trará benefícios à ECT.

\subsection{Lojas de distribuição}

Também para esse grupo de lojas é possível perceber que algumas lojas eficientes se destacam como referenciais para outras ineficientes (ver Tabela 2). Em particular, a loja LD22 serve de referencial para outras 11 lojas; a LD15 para outras 7; a LD27 para outras 6; e as lojas LD6 e LD14 para outras 5. Cabe ressaltar que a loja LD18 não aparece como referencial para nenhuma outra loja, sendo classificada pela técnica DEA como sui generis, não podendo ser comparada à nenhuma outra. $\mathrm{O}$ fato ilustra mais uma característica da técnica: se uma loja não pode ser comparada à nenhuma outra, não pode ser considerada não eficiente.

\subsection{Lojas integradas}

A Tabela 3 mostra que a loja LI50 serve de referencial para outras 32 lojas; a LI18 para outras 15; a LI47 para outras 14; e a LI19 para outras 13. As lojas LI2, LI4, LI14, LI17, LI51 e LI13 são consideradas sui generis pela técnica. Portanto, dadas as suas caraterísticas, são consideradas com $100 \%$ de eficiência relativa. A análise completa das lojas que serviram de benchmarking em seus respectivos grupos (atendimento, distribuição e integradas) pode ser encontrada em Prado (2000).

\subsection{Comparação entre DEA e sistemática de avaliação atual}

Para aumentar a compreensão dos gestores da ECT sobre o processo de avaliação da eficiência relativa das lojas, compararam-se os índices de desempenho medidos por meio do R/D aos índices de eficiência relativa gerados pela DEA, tendo por base o ano de 1999. Para fins comparativos foram utilizadas somente as lojas de atendimento e as integradas, pois o grupo de lojas de distribuição não tem calculado o indicador R/D ou qualquer outra forma de avaliação em vigência que pudesse ser comparada aos índices obtidos com a técnica DEA. Os dados estão apresentados nas Tabelas 1 e 3.

Segundo a avaliação pelo índice $\mathrm{R} / \mathrm{D}$, todas as lojas de atendimento mostram-se eficientes, visto que atingiram índice superior a 1 (Tabela 1). A avaliação feita por meio do DEA mostrase mais restritiva, pois apenas 15 lojas $(50 \%$ do total) tiveram eficiência relativa igual a $100 \%$. A comparação entre os índices das lojas integradas também mostra essa peculiaridade: 50 lojas (91\% do total) têm índice R/D igual ou superior a 1, enquanto apenas 21 lojas (38\% do total) apresentam índice de eficiência relativa igual a 100\%. O coeficiente de correlação linear de Pearson entre os dois conjuntos de índices valem 0,44 e 0,60 , respectivamente, para as lojas de atendimento e as integradas, evidenciando que as avaliações possuem características distintas. Do conjunto das 85 lojas de atendimento e integradas analisadas, somente 5 (6\% do total) são consideradas ineficientes pelo índice R/D. A mera utilização desse índice, que engloba somente variáveis de natureza financeira, pode prejudicar significativamente a avaliação, obscurecendo importantes diferenças existentes entre 
as diversas lojas. Por outro lado, a análise efetuada com a técnica DEA permite melhor discriminação entre as lojas, potencializando a obtenção de valiosas informações em busca de melhorias globais de performance do sistema. Do conjunto dessas 85 lojas, apenas 36 (42\% do total) foram consideradas relativamente eficientes.

Evidencia-se que a avaliação por meio do índice R/D, dada sua natureza estritamente financeira, é muito limitada. A utilização da técnica DEA permite maior abrangência de variáveis na avaliação. Em síntese, a ferramenta DEA permite maior flexibilidade na avaliação, desde a seleção das lojas e escolhas dos fatores até a possibilidade de indicar possíveis pontos a serem melhorados em cada loja.

\section{Avaliação dos resultados}

A análise dos grupos de lojas da ECT, utilizando a técnica DEA, permitiu apontar algumas metas que deveriam ser atingidas pelas lojas consideradas não eficientes. Parte-se da identificação, para cada loja não $100 \%$ eficiente, de grupos de lojas denominados pares, que servem para compor quantitativamente suas metas. Cabe lembrar que os resultados quantitativos obtidos devem passar necessariamente por avaliação de caráter qualitativo. Nem todas as metas poderão ser implementadas na realidade imediata, mas poderão servir como orientação gerencial a ser seguida. A orientação oferecida pelo modelo pode conduzir a um processo de reflexão sobre a utilização dos recursos e os resultados obtidos em cada loja, comparativamente às demais lojas.

Visando a complementar a análise das lojas pares, que serviram de referencial para compor as metas das lojas não eficientes, em cada grupo, foram realizadas algumas visitas in loco e entrevistas (por telefone) a 30 lojas do total das 113 analisadas no estudo (26,5\%). As lojas visitadas ou entrevistadas incluem tanto lojas $100 \%$ eficientes como não $100 \%$ eficientes. Por conveniência, a seleção das lojas visitadas baseou-se na proximidade geográfica em relação à REOP Santo Ângelo (lojas das regiões operacionais de Santa Maria, Passo Fundo e Panambi). As entrevistas por telefone, por outro lado, incluíram lojas das regiões operacionais de Novo Hamburgo, Pelotas, Porto Alegre, Santa Cruz do Sul e Caxias do Sul. O objetivo do contato com as lojas eficientes foi perceber quais práticas gerenciais locais vêm sendo adotadas que possam servir de referencial para o grupo de lojas consideradas não $100 \%$ eficientes. Já para o grupo de lojas não $100 \%$ eficientes, informações foram coletadas no sentido de comparar se aquelas práticas são realizadas de forma idêntica ou distinta em relação ao grupo de lojas $100 \%$ eficientes. Como base referencial para comparação, foram utilizados os fatores de input e output operacionalizados para o modelo DEA. O roteiro de entrevistas procurou questionar que procedimentos gerenciais específicos são adotados pelas lojas em relação a cada uma dessas variáveis.

Focalizando as práticas gerenciais locais, podese categorizar os fatores em relevantes e não relevantes para efeitos de análise. De fato, constatase que alguns estão mais diretamente sob controle dos gestores das lojas. Esses fatores, denominados relevantes, são: número de funcionários, custo total, tempo de treinamento por funcionário, programa de qualidade, receita total e carga de trabalho. Há, porém, outros fatores para os quais os procedimentos gerenciais do gestor têm pouca influência, como: área física da loja (definida corporativamente); número de objetos distribuídos (dependente da demanda); população atendida (as campanhas e trabalhos para atrair novos clientes ainda são incipientes, estando atreladas basicamente à ECT como um todo); e número de veículos (definida corporativamente). Estes foram denominados fatores não relevantes. Essa categorização reflete práticas gerenciais adotadas correntemente pela ECT. Espera-se que a eventual incorporação da análise DEA pela ECT possa levar a um questionamento de todos os fatores, inclusive dos aqui denominados não relevantes.

Os fatores relevantes têm sido trabalhados de forma diferente nas lojas analisadas. Algumas práticas gerenciais locais observadas em lojas $100 \%$ eficientes são apresentadas a seguir. 
Prática A - Treinamento em local de trabalho de forma sistematizada, com cronograma definido ou pelo surgimento de novos procedimentos. $\mathrm{O}$ treinamento é descentralizado, utilizando instrutores da própria equipe de trabalho para que os funcionários possam participar como condutores desses eventos.

Prática B - Preocupação dos gestores incentivando o aperfeiçoamento individual de seu grupo de trabalho, seja aproveitando o programa corporativo da empresa, plano diretor de educação empresarial (PDEE), seja oferecendo cursos locais.

Prática $\boldsymbol{C}$ - Preocupação dos gestores com o trabalho em equipe, com a descentralização de responsabilidades e criação de canais de comunicação (reuniões, seminários, cursos, palestras e confraternizações) e com o envolvimento dos funcionários.

Prática $\boldsymbol{D}$ - Debates sobre ações a serem implementadas de forma a atingir as metas estabelecidas para o índice de satisfação no atendimento (ISA), adotando práticas diferenciadas de atendimento aos clientes. Exemplos dessas práticas são: atendimentos personalizados, préatendimentos, construção de espaço para estacionamento, instalação de condicionadores de ar nas lojas, identificações internas e externas e outras. Essas atitudes visam a uma maior interação e aproximação com o cliente.

Prática $\boldsymbol{E}$ - Descentralização dos critérios do programa de qualidade para a equipe de trabalho, com descentralização das responsabilidades na condução do processo. Essa prática demonstra ações para melhoria do ambiente de trabalho e preocupação com os processos de trabalho nas lojas, reforçando a idéia de continuidade das melhorias, na visão de alguns gestores.

Prática $\boldsymbol{F}$ - Estabelecimento de metas diárias para as equipes de vendas e atendimento, com premiações. As campanhas são elaboradas localmente (com reduzido apoio corporativo), sendo a premiação realizada, muitas vezes, com recursos dos próprios funcionários.
Prática $\boldsymbol{G}$ - Definiçãa de carteiras de clientes de atacado (clientes com contrato com a ECT e grandes clientes), adotando visitas regulares. Planejamento e realização de visitas para clientes de varejo, com média de 6 a 10 visitas mensais.

Prática $\boldsymbol{H}$ - Acompanhamento dos resultados das campanhas e resultados financeiros das lojas, adotando instrumentos próprios ou da REOP correspondente, pois os instrumentos corporativos disponibilizam informações com atrasos.

As práticas A, B e C mostram a preocupação do gestor com o desenvolvimento de sua equipe de trabalho e com a melhoria do ambiente de trabalho para os clientes internos. As práticas $F, G$ e $\mathrm{H}$ refletem a preocupação dos gestores com os resultados financeiros de suas lojas, buscando tomar atitudes comerciais para ampliação de receitas e obtenção de metas comerciais. A prática D demonstra a preocupação dos gestores com a satisfação de seus clientes, enquanto a prática $\mathrm{E}$, com a condução do programa de melhoria do ambiente de trabalho (PMAT).

O Quadro 3 relaciona tais práticas às lojas visitadas ou entrevistadas. Percebe-se que as práticas que envolvem atitudes mais participativas tendem a estar mais concentradas nas lojas $100 \%$ eficientes. De fato, as práticas apontadas foram percebidas com menor intensidade nas lojas não $100 \%$ eficientes, havendo pouca descentralização, equipes menos coesas e poucas atitudes comerciais (baixo número de visitas, não adoção de carteiras de clientes e não fixação de metas). Foi percebido, também, que alguns gestores conhecem as atitudes que precisariam ser adotadas em relação à equipe ou grupo de trabalho, embora não o façam.

Para dois dos fatores relevantes, custo total e carga de trabalho, não foram associadas práticas gerenciais locais capazes de diferenciar lojas 100\% eficientes de lojas não $100 \%$ eficientes. Não há projeto em desenvolvimento nas lojas visitadas ou entrevistadas visando à redução de custos. Talvez isso ocorra em razão da centralização da gestão de custos na diretoria. Muitos gestores informaram que não lhes compete trabalhar esse fator. 
Quadro 3 - Demonstrativo final de práticas relevantes em cada grupo de lojas.

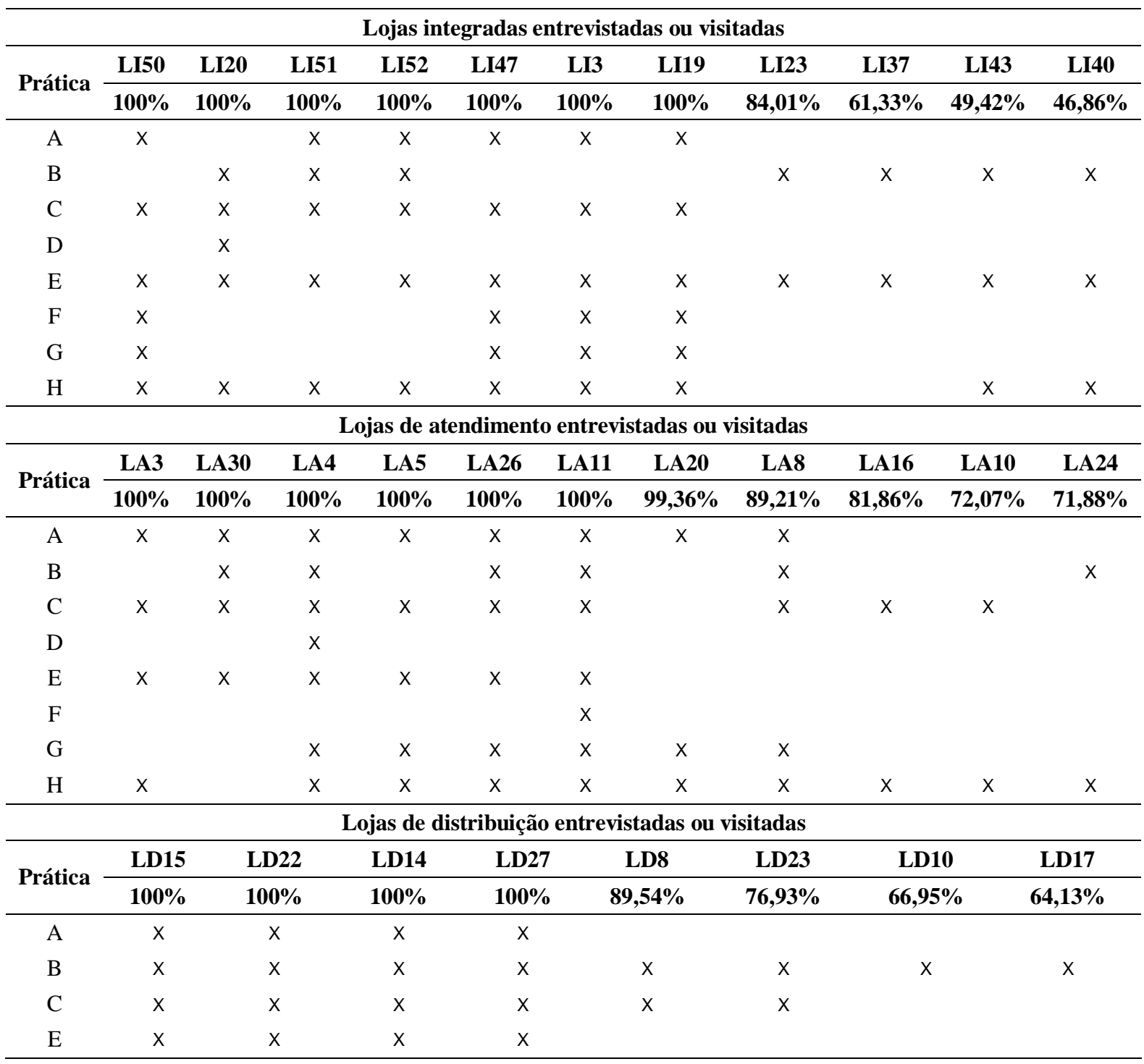

Já o sistema de carga de trabalho revela-se pouco conhecido pelos gestores. Esse sistema define a classificação das lojas em categorias, a qualificação necessária para o gestor da loja, bem como a gratificação (remuneração) da função de gestor.

Os dados para composição desse fator são centralizados pela gerência de atendimento e pouco comunicados ou divulgados para as lojas. Não há ação alguma das lojas para uma gestão da produtividade dos funcionários.

\section{Considerações finais}

O presente trabalho mostrou a utilização da técnica DEA para medir a eficiência relativa das lojas da ECT, na Diretoria Regional do Rio Grande do Sul, comparando-a à sistemática de avaliação financeira, denominada $\mathrm{R} / \mathrm{D}$, utilizada atualmente. A técnica demonstrou ser apropriada para a utilização na avaliação de eficiência das lojas da ECT. Além de abranger muitos fatores, que atualmente não são considerados para a 
avaliação das lojas, tem flexibilidade para admitir possíveis inclusões ou exclusões de fatores que sejam importantes estrategicamente no julgamento dos administradores.

O DEA é uma ferramenta conhecida mundialmente por apresentar acentuada utilização para medir a eficiência de empresas públicas e privadas, como escolas, hospitais, universidades e outras. Ao contrário de outras técnicas, o DEA proporciona mapeamento em escala relacional, mais interessante do que um simples ordenamento (ranking), mostrando o quanto uma DMU é mais ou menos eficiente que outra e que fatores determinam essas distintas eficiências. A técnica também permite cruzar diferentes fatores sem precisar reduzi-los a uma única base. Mas talvez mais importante que a obtenção de uma escala relacional de eficiência, a aplicação da técnica na ECT, dadas as suas características, estimulou a criatividade nas práticas gerenciais locais, disseminando-as. As boas práticas valorizaram-se.

Quanto ao conjunto de lojas analisadas pela técnica DEA, cabe ressaltar que os resultados obtidos pela modelagem matemática são de certa forma estáticos e baseados nos fatores de input e output selecionados. As metas propostas pela técnica, muitas vezes, podem não espelhar a realidade ou a possibilidade real de alcance; cabe aos administradores tomá-las como um referencial. Cada loja precisa ser analisada dentro de sua realidade ou contexto organizacional. Portanto, mesmo aquelas que atingiram $100 \%$ de eficiência relativa, podem não ter o desempenho desejado pela organização. Enfim, cabe aos administradores da ECT uma análise dos resultados obtidos pelo DEA nas práticas realizadas pelas lojas, nas contribuições dos gestores para o aperfeiçoamento do modelo e na comparação obtida nas duas formas de avaliação. A seguir estão relacionadas algumas contribuições fornecidas por gerentes de lojas visitadas ou entrevistadas após a apresentação dos resultados, visando ao aperfeiçoamento e à extensão do modelo, segundo o entendimento e a percepção dos mesmos.

- Inclusão da pontuação de outro programa corporativo da DR/RS, denominado sistema de avaliação de gestão (SAG), que deverá gradativamente substituir o atual PMAT.

- Inclusão do número de lojas operadas por terceiros e coordenadas pela loja.

- Inclusão de um índice de tempo médio de espera na fila de cada loja.

- Inclusão do número de clientes em carteira, número de visitas aos clientes e o crescimento agregado de receitas desses clientes.

- Inclusão do índice de absenteísmo em cada loja.

- Inclusão do número de objetos com vestígio (rastreamento) entregues e coletados diariamente.

- Inclusão de um indicador de escolaridade por loja.

Em resumo, esses são os fatores apontados pelos gerentes das lojas para extensão do atual modelo. Para a efetiva incorporação das sugestões há que se considerar a possibilidade de captação desses dados e sua relevância estratégica para a administração da ECT do Rio Grande do Sul.

Como todo estudo aplicado, as principais limitações deste trabalho dizem respeito a seu poder de generalização. Embora reconheça-se e salientese a generalidade analítica do estudo, seus resultados não podem ser extrapolados para outras situações não contempladas. Em particular, chama-se a atenção para a dificuldade de obtenção de dados e sua confiabilidade, encontrada no presente estudo. Houve dificuldade na definição final dos fatores, pois para muitos deles, apesar de serem considerados relevantes, a coleta de dados foi impossível, em razão de seu grau de dispersão e de inexistência, por parte da empresa, de métodos estabelecidos de coleta regular. De outra parte, como característica intrínseca da metodologia DEA, deve ser ressaltado que os índices de eficiência relativa encontrados dependem diretamente do particular conjunto de fatores de input e output escolhidos.

Deve ser também ressaltado que as contribuições das práticas gerenciais aqui apresentadas estão baseadas na percepção dos gestores das lojas entrevistadas. Apesar das limitações apontadas, acredita- 
se ter sido demonstrada a possibilidade de avaliação de desempenho das lojas, alargando a visão exclusivamente financeira, empregando o cruzamento de vários recursos disponíveis nas lojas, utilizados com diferentes enfoques e distintas intensidades. Recomenda-se à ECT: que as práticas identificadas como relevantes no Quadro 3, sendo observadas nas lojas consideradas relativamente eficientes, sejam repassadas às consideradas relativamente não eficientes; que se efetue uma análise das prá- ticas operadas nas lojas não eficientes, verificando os elementos que contribuíram para o resultado obtido por meio do modelo; que se atenda às observações feitas pelos gestores das lojas para que o modelo seja complementado e expandido, incluindo outras variáveis consideradas importantes e que estão refletidas no dia-a-dia das lojas; e que se usem pesos distintos para os fatores, conforme a visão dos administradores sobre a relevância estratégica de cada fator.

\section{Referências Bibliográficas}

ACKOFF, R. L.; SASIENI, M. W. Pesquisa operacional. Rio de Janeiro: LTC, 1977.

BANDEIRA, D. M.; BECKER, J. L.; BORENSTEIN, D. Eficiência relativa dos departamentos da UFRGS utilizando DEA. Recitec - Revista de Ciência e Tecnologia, v. 5, n. 1, p. 116-143, 2001.

BERGENDAHL, G. DEA and benchmarks - an application to Nordic banks. Annals of Operations Research, v. 82, p. 233-249, 1998.

BRASIL, Mãos à obra Brasil. Proposta de Governo. Presidente Fernando Henrique Cardoso, Brasília, 1994.

BRASIL, PASTE - Programa de Recuperação e Ampliação do sistema de Telecomunicações e do sistema Postal. Brasília: Ministério das Comunicações, 1995.

BRASIL, Avança Brasil. Proposta de Governo. Presidente Fernando Henrique Cardoso, Brasília, 1998.

CANADA, J. R.; SULLIVAN, W. G. Economic and multiattribute evaluation of advanced manufaturing systems. Englewood Cliffs: Pretentice Hall, 1989.

CHARNES, A.; COOPER, W. W.; RHODES, E. Measuring the efficiency of the decision making units. European Journal of Operational Research, v. 2, p. 429-444, 1978.

CHARNES, A.; COOPER, W. W.; LEWIN, A. Y. Data Envelopment Analisys: theory, methodology and aplication. Massachussets: Kluwer Academic Publishers, 1994.

COOPER, W.; SEIFORD, L. M.; TONE, K. Data Envelopment Analysis - A comprehensive text with models, applications, references. Massachussets: Kluwer Academic Publishers, 1999.

COSQUER, Y. Diretiva Postal: um documento legal da união européia para regularização de serviços postais. Informativo União Postal Universal. Berna: UPU, 1997.
ECT, Manual de Comercialização e Atendimento MANCAT. Brasília: ECT, 1990.

ECT, Administração Central. Informativo da Presidência. Discurso de posse do presidente Egydio Bianchi: Brasília, 1999.

IBGE, Anuário estatístico do Brasil. Rio de Janeiro: IBGE, 1996.

MAÇADA, A. C. G.; BECKER, J. L. Measuring the efficiency of investiments in information tecnology in brazilian banks. In: GUPTA, O. K. Operations and quantitative management in the global business environment. Proceedings of the second international conference on operations and quantitative management (ICOQM), Ahmedabad. New Delhi: Tata McGraw-Hill, jan. 1999. p. 248255.

MORGAN, D. L. Focus groups as qualitative research. Beverly Hills: Sage, 1988.

PRADO, V. J. Avaliando a eficiência das lojas da ECT do Rio Grande do Sul. 2000. Dissertação (Mestrado) - PPGA/EA/UFRGS, Porto Alegre, Rio Grande do Sul.

PRAZERES, P. M. Dicionário de termos da qualidade. São Paulo: Atlas, 1996.

SEIFORD, L. M. A bibliography for data envelopment analysis. Annals of Operations Research, 73, p. 393-438, 1997.

SHAFER, S. M.; BYRD, T. A. A framework for measuring the efficiency of organizational investments in information technology using data envelopment analysis. Omega, v. 28, p. 125-141, 2000.

WARWICK WINDOWS DEA, User's Guide Windows version 1.10. Warwick: University of Warwick, 1997. 


\section{Anexo - Definição das variáveis de input e output}

\begin{tabular}{|c|c|c|}
\hline \multirow{5}{*}{ Input } & nfunc & $\begin{array}{l}\text { Número de funcionários alocados ou lotados na loja. Os dados foram obtidos a partir do cadastro de } \\
\text { pessoal utilizado pela gerência de recursos humanos da empresa, confirmados nas regiões } \\
\text { operacionais que coordenam as lojas, tendo por base o mês de dezembro de } 1999 \text {. }\end{array}$ \\
\hline & áre-fís & $\begin{array}{l}\text { Espaço físico ocupado pela loja para a prestação dos serviços de atendimento aos clientes. Os dados } \\
\text { foram retirados do cadastro de imóveis da gerência de administração da empresa, confirmados nas } \\
\text { lojas. Foi usado por base o ano de } 1999 \text {. }\end{array}$ \\
\hline & custos & $\begin{array}{l}\text { Despesas gerais que a loja realiza. Incluem despesas com salários, manutenção, remuneração da rede } \\
\text { de terceiros, rateios, material de consumo, melhorias físicas, aluguel, água, luz e transporte. Para fins } \\
\text { do estudo, foi utilizada a média mensal de gastos que a loja efetuou durante o ano de 1999. Os dados } \\
\text { foram obtidos por meio de um relatório denominado movimento financeiro de agências (MFA), } \\
\text { emitido mensalmente pela gerência financeira da empresa. }\end{array}$ \\
\hline & h_ep & $\begin{array}{l}\text { Número médio de horas de treinamento recebido por empregado da loja. São considerados } \\
\text { treinamento todos os eventos externos e internos (corporativos), os treinamentos realizados no local } \\
\text { de trabalho (TLT), horas-aula recebidas durante o compartilhamento do plano diretor de educação } \\
\text { empresarial (PDEE) que a ECT oferece para funcionários, visando à formação em } 1^{\circ}, 2^{\circ} \text { e } 3^{\circ} \text { graus e } \\
\text { pós-graduação. Os dados foram obtidos na gerência de recursos humanos da diretoria do Rio Grande } \\
\text { do Sul, tendo por base o ano de } 1999 \text {. }\end{array}$ \\
\hline & n_veíc & $\begin{array}{l}\text { Número de veículos motorizados (carros e motos) utilizados pela loja na prestação dos serviços. Os } \\
\text { dados foram obtidos do cadastro da gerência de transporte, confirmados por pesquisas nas lojas, tendo } \\
\text { por base o mês de dezembro de } 1999 \text {. }\end{array}$ \\
\hline \multirow{6}{*}{ Output } & in_papt & $\begin{array}{l}\text { Índice obtido pela multiplicação do número de pessoas (média por dia) atendidas em cada loja pelo } \\
\text { número de lojas existentes no município e dividido pela população total do município atendido pela } \\
\text { respectiva loja. Obtém-se, assim, um indicador de prestação de serviços para a comunidade, de acordo } \\
\text { com o local onde cada loja atua. Pode-se configurar esse fator como um indicador de atratividade, } \\
\text { visando ao aproveitamento da loja como ponto de prestação de serviços e comercialização de } \\
\text { produtos. Um maior volume de negócios (prestação de serviço) poderia estar ligado à passagem de } \\
\text { pessoas pela loja. Para isso, foi realizada pesquisa nas lojas, buscando-se, por meio de documentos } \\
\text { financeiros (relatórios de caixa), a quantidade média por dia de pessoas que são atendidas na loja. Para } \\
\text { fins de melhorar a visualização da análise, multiplicou-se esse índice por 1.000, sem alteração de sua } \\
\text { essência. Os dados de população total foram obtidos no IBGE (IBGE, 1996). }\end{array}$ \\
\hline & in_isa & $\begin{array}{l}\text { Índice obtido pela loja na pesquisa anual feita pela ECT para verificar a satisfação de seus clientes } \\
\text { quanto ao atendimento de suas lojas. Os critérios utilizados na pesquisa são: apresentação pessoal dos } \\
\text { funcionários; cortesia dos funcionários; clareza nas informações prestadas; tempo de espera na fila; } \\
\text { rapidez dos funcionários; organização geral da loja; sinalização interna e externa; conforto e facilidade } \\
\text { de acesso. O índice máximo é } 100 \% \text { de satisfação. As informações foram obtidas na gerência de } \\
\text { atendimento, tendo por base o ano de } 1999 \text {. }\end{array}$ \\
\hline & in_pmat & $\begin{array}{l}\text { Pontuação obtida pela loja no programa de qualidade da empresa. A pontuação é obtida por meio da } \\
\text { auto-avaliação de cada loja e da avaliação feita pela equipe de avaliadores das regiões operacionais, } \\
\text { coordenadora da loja. Os critérios utilizados pelo programa são: seleção, utilização e descarte; } \\
\text { organização, arrumação e sistematização; limpeza, inspeção e zelo; asseio, higiene, saúde, } \\
\text { autodisciplina, autocontrole e educação. A pontuação máxima é de } 1.000 \text { pontos. Os dados foram } \\
\text { obtidos com a assessoria de planejamento e gestão (APEGE), tendo por base o ano de } 1999 \text {. }\end{array}$ \\
\hline & receitas & $\begin{array}{l}\text { Receitas totais médias mensais obtidas pela loja por meio da prestação e venda de produtos e serviços. } \\
\text { Os dados foram obtidos do relatório denominado de movimento financeiro de agências (MFA), } \\
\text { emitido mensalmente pela gerência financeira, tendo por base o ano de } 1999 \text {. }\end{array}$ \\
\hline & sct & $\begin{array}{l}\text { Indicador da carga de trabalho no atendimento a partir dos serviços realizados na loja, obtido do } \\
\text { sistema de medição mensal da carga de trabalho das lojas, efetuada pela gerência de atendimento. O } \\
\text { indicador é definido tomando por base o tempo-padrão de cada serviço prestado, acumulando pontos. } \\
\text { Não há, em princípio, pontuação máxima. Foi utilizado por base o ano de } 1999 \text {. }\end{array}$ \\
\hline & objdist & $\begin{array}{l}\text { Número médio diário de objetos distribuídos nos domicílios dos clientes por intermédio de cada loja. } \\
\text { Os dados foram obtidos dos relatórios informativos da gerência de operações e logística, confirmados } \\
\text { nas regiões operacionais coordenadoras de cada loja, tendo por base o ano de } 1999 \text {. }\end{array}$ \\
\hline
\end{tabular}




\title{
EVALUATING THE ECT STORES EFFICIENCY IN RIO GRANDE DO SUL
}

\begin{abstract}
Postal companies around the world have been seeking methods to support their operational practices in order to keep or increase their market share. The Brazilian Mail and Telegraph Company (ECT), established since 1969, offer a portfolio of products and services to its customers through several similar postal offices all over Brazil. The units use several resources in different intensities, currently having their performance evaluated by a single economical factor: revenue over expense. We propose a new method of evaluation, using Data Envelopment Analysis (DEA), a linear programming technique that makes possible the inclusion of other factors beyond the simplistic and purely economical approach. We make our point using a set of units in the state of Rio Grande do Sul. The objectives of this paper are: 1 . to define which factors can be used to evaluate the units; 2 . to define sets of similar units that develop the same functions, but differ only in the intensity of resource usage; 3. to generate, through the technique, the results of the evaluation process, obtained from the defined quantitative factors, providing a sensitivity analysis; and 4. to provide useful information to help managers in their decision making process. Using the technique made possible: 1. to identify factors used in different intensities in different units; 2. to identify practices used by $100 \%$ efficient units, that can contribute to improve non efficient units; and 3. to allow and to encourage the participation of local managers in the modification and extension of the model observing particular features of their units.
\end{abstract}

Key words: efficiency analysis, DEA, services management. 